\title{
Three New Species of the Genus Microplitis Förster, 1862 (Hymenoptera: Braconidae: Microgastrinae) from Saudi Arabia
}

\author{
Hamed A. Ghramh, , 2,3, Zubair Ahmad 1, 2, 4, Khalid Ali Khan 1, 2,3* and Farhat Khan \\ ${ }^{1}$ Research Center for Advanced Materials Science (RCAMS), King Khalid University, \\ P.O. Box 9004, Abha 61413, Saudi Arabia \\ ${ }^{2}$ Unit of Bee Research and Honey Production, Faculty of Science, King Khalid \\ University, P.O. Box 9004, Abha 61413, Saudi Arabia \\ ${ }^{3}$ Biology Department, Faculty of Science, King Khalid University, P.O. Box 9004, Abha \\ 61413, Saudi Arabia \\ ${ }^{4}$ Biology Department, Faculty of Arts and Sciences, King Khalid University, Dhahran \\ Al Janoub, Saudi Arabia

\section{A B S T R A C T} \\ In this study, Microplitis tihamicus sp. nov., M. faifaicus sp. nov. and M. khamisicus sp. nov. (Hymenoptera: \\ Braconidae: Microgastrinae) are described. The genus Microplitis is recorded for the first time from Saudi \\ Arabia. Characters of these new species and their affinities with related species are discussed.
}

\section{INTRODUCTION}

$\mathrm{T}$ he members of the genus Microplitis are solitary or gregarious endoparasitoids (koinobiont) of lepidopteron larvae. The genus Microplitis was erected by Foerster (1862) with Microgaster sordipes Nees von Esenbeck as its type species. It is characterized by having fore wings with large areolet, mesopleuron without prepectal carina, propodeum roughly sculptured and often with a median longitudinal carina, and metasomal tergites 2 and 3 unsculptured with a weak suture between them (Nixon, 1970; Mason, 1981; Austin and Dangerfield, 1992, 1993; Fernandez-Triana and Boudreault, 2018). The genus Microplitis contains 190 species worldwide (FernándezTriana and Ward, 2017; Yu et al., 2016; Zhang et al., 2019; Fernandez-Triana et al., 2020). Technically, no species have been listed from the Arabian region, though the existence of eight morpho-species recorded by FernándezTriana and van Achterberg (2017). At present, five species of Microplitis are reported from the afro-tropical region (Yu et al., 2016).

Despite the vast size and diverse topography of Saudi Arabia, studies on the terrestrial fauna especially insects, have not been substantially explored. Among the hymenopteran parasitoids, the family Braconidae contains only 35 species from Saudi Arabia (Ghramh and Ahmad,

\footnotetext{
* Corresponding author: khalidtalpur@hotmail.com 0030-9923/2020/0006-2185 \$ 9.00/0

Copyright 2020 Zoological Society of Pakistan
}

2016). Within such a large expanse of land, covering more than 2.15 million $\mathrm{km}^{2}$, with only two species of subfamily Microgastrinae (Braconidae) had been recorded from Saudi Arabia (Fernández-Triana and van Achterberg, 2017). In this paper, we provide descriptions of three new species of the braconid genus Microplitis Förster in order to study the biodiversity and conservation of parasitoid wasps in the Kingdom of Saudi Arabia. Southwest region of Saudi Arabia is divided by the steep Rocky Mountains into two main subdivisions, a lowland coastal plain at the west, known as "Tihama" and a mountainous area with an elevation of 3,000 m highlands at its peak at the east, known as "Asir Mountains range (Alahmed et al., 2010). Although the geographical location of the southwestern region of Saudi Arabia is debatable, many workers have considered it to belong to the Afrotropical region (Sclater, 1858; Wallace, 1876; Hölzel, 1998). Studies of several taxonomic groups of insects have revealed that this region has an apparent faunal similarity with the Afrotropical region (Cowie, 1989; Sharaf et al., 2014; El-Hawagry and Al Dhafer, 2015; Abdel-Dayem et al., 2018).

\footnotetext{
Abbreviations

$\mathrm{C}$, Costa; SC, subcosta; 1-R1, first radius; $r$, transverse radial vein; 1-SR , first sectio radii; $2-\mathrm{SR}$, second sectio radii; $1 \mathrm{SR}+\mathrm{M}$, First median sectio radii; $1-\mathrm{M}$, first media; $\mathrm{r}-\mathrm{m}$, transverse radio-medial vein; $\mathrm{M}+\mathrm{CU}$, medio-cubital vein; 1-CU1, first cubital vein; 2-CU1, Second cubital vein; AOL, anterior ocellar line; POL, posterior ocellar line; OD, maximum diameter of ocelli; OOL, ocelo-ocular line; F, Flagellomere; T1, First metasomal tergite; T2, Second metasomal tergite; ZDKKU, Department of Zoology, King Khalid University, Abha, Saudi Arabia.
} 


\section{MATERIALS AND METHODS}

The specimens were collected by Malaise trap from the south-western region (Asir) of Saudi Arabia. Three braconid species were encountered in this research. The collected specimens were card-mounted on triangular points, then were examined with a stereoscopic microscope Nikon SMZ1000 and metric characters were measured with an ocular micrometer. To observe the detailed characters of the wings, these fore and hind wings were detached from the body, cleared and placed in Canada Balsam, and observed under a compound light microscope. Absolute measurements are used for body length in $\mathrm{mm}$. We have followed van Achterberg (1993) for the terminologies of various body parts and wing venation, and Eady (1968) for the terminology of micro-sculpture. Classification, nomenclature and distributional data of Braconidae suggested by Yu et al. (2016) have been followed. Digital SEM photographs were taken at the department of Physics, King Khalid University, Abha, with a JEOL JSM 6360 LA (Japan) in low vacuum mode. The type specimens were deposited in the Insect Collection of the Department of Zoology, King Khalid University, Saudi Arabia (ZDKKU).

\section{RESULTS AND DISCUSSION}

\section{Microplitis Förster, 1862}

Microplitis Förster, 1862: 245 [type species, by original designation, Microgaster sordipes Nees ab Esenbeck, 1834] Nixon, 1970: 3. Mason, 1981: 132. Austin and Dangerfield, 1992 (see Shenefelt (1973: 737) for complete bibliography].

Dapsilotoma Cameron, 1906: 101 (type species, by monotypy, Dapsilotoma testaceipes Cameron, 1906). Synonymized by Viereck (1914: 25).

Glabromicroplitis Papp, 1979: 176 (type species, Glabromicroplitis mahunkai Papp, 1979). Synonymized by Austin and Dangerfield (1992).

Diagnosis (after Austin and Dangerfield, 1993; Ranjith et al., 2015).

Clypeal margin concave to straight; eyes large and densely setose; width of face (at widest) $0.5 \times$ width of head; labial palps nearly always with three segments, rarely with four segments; pronotum with lateral furrow; mesoscutum usually with some sculpturing, sometimes completely smooth; notauli variable, ranging from virtually absent to strongly impressed and coarsely sculptured; posterior band of scutellum usually wide and smooth, interrupted medially by rugosity; pretectal carina absent; propodeum usually convexly rounded, rarely composed of two faces meeting transversely and then not at an acute angle, virtually always with a distinct percurrent medial keel, never with an areola, surface coarsely sculptured, usually rugose to reticulate-rugose; hind coxa usually small, shorter than $\mathrm{T} 1$; hind tibial spurs subequal in length, short, usually reaching less than $0.3-0.4 \times$ distance to hind basitarsus; fore wing usually infuscate, with 1-R1 short, not reaching to SR1; $1 \mathrm{CU}-1$ variable in length but always shorter than $2 \mathrm{CU}-$ 1; r-m present; vennal lobe convex and setose throughout; metasoma with $\mathrm{T} 1$ much longer than wide, often parallel sided or tapering towards apex; suture between T2 and T3 faintly defined or absent, if defined then T2 usually shorter than T3, rarely equal in length; sometimes with indistinct median field on T2; metasoma apart from T1 smooth; hypopygium usually well sclerotized, never membranous and expandable, sometimes elongate medially; ovipositor usually very short, often slightly down-curved throughout length, sheaths rarely protruding much beyond apex of hypopygium, nearly always with long hairs on exposed part, often setose apically.

\section{Microplitis tihamicus Ghramh and Ahmad, sp. nov.} (Fig. $1 \mathrm{~A}-\mathrm{C}$ )

\section{Material examined \\ Holotype: †, Saudi Arabia: Abha, Almanaf, (18 $11^{\prime} 52.1^{\prime \prime} \mathrm{N} 42^{\circ} 33^{\prime} 00.5$ 'E), 7.VIII.2017, Malaise trap, Z. Ahmad leg. (ZDKKU). Paratype, 1 , , with same data as holotype (HB-11, ZDKKU).}

\section{Description}

Female: body length: $2.2 \mathrm{~mm}$; length of fore wing: $1.8 \mathrm{~mm}$; length of antenna: $1.8 \mathrm{~mm}$.

\section{Differential diagnosis}

The new species closely resembles with Microplitis isis (de Saeger, 1944) from Congo; however, it can be separated from all other described species of Microplitis in the afro-tropical region by the combination of the following features: small size (body length 2.1-2.2 mm, fore wing length $1.7-1.8 \mathrm{~mm}$ ), entirely dark brown to black coloration (excluding yellowish legs), slightly infuscate wings.

\section{Head}

Head ca. $2 \times$ as wide as long in dorsal view, subcircular in anterior view; length of eye $0.8 \times$ as long as temple in dorsal view; OOL: POL: AOL: $O D=6: 3: 2: 1.5$; inner margin of eyes subparallel; face distinctly convex medially, flattened laterally and punctuate-rugose with faint trace of median longitudinal carina; clypeus smooth and evenly convex; malar space ca. $2 \times$ as long as its basal width of mandible; vertex dull with micro punctures; lateral temples punctuate-rugose and moderately setose; antenna about as 
long as body with 14-segmented flagellomeres, F 1 as long as F 2 , apical flagellomere pointed.

\section{Mesosoma}

Mesosoma $1.35 \mathrm{x}$ as long as wide; mesoscutum dull, rugulose with hairs medially while lateral sides and posterior side smooth, notauli indistinct (Fig. 1A); scutellum smooth, scutellar lunules wide divided by seven carinae, pre-scutellar furrow poorly developed without any groove, medio-posterior depression of scutellum elliptical (Fig. 1A); propodeum reticulate rugose with a percurrent medial longitudinal carina, its sculpture rather prominent (Fig. 1A); mesopleuron rugulose anteriorly, rest is smooth; length of hind femur $3.1 \times$ its width; length of hind tibia $6.0 \times$ its width; length of hind tibial spurs $0.30,0.25 \times$ hind basitarsus; hind tarsal claw normal size.

\section{Wings}

Fore wing $2.5 \times$ as long as wide; pterostigma $2.2 \times$ as long as wide; $1-\mathrm{R} 1$ ca. $0.8 \times$ length of pterostigma; 1-M straight (Fig. 1C); 1SR $+\mathrm{M}$ almost straight; areolet somewhat triangular, 3-SR hardly extending from origin, perpendicular to vein $\mathrm{r}$ (Fig. 1C); 1-CU1 $0.33 \times$ as long as 2-CU1; 2- CU1 slightly curved posteriorly; angle between $\mathrm{C}+\mathrm{SC}+\mathrm{R}$ and $1-\mathrm{SR} 90^{\circ}$

\section{Metasoma}

T1 $1.8 \times$ as long as wide with a prominent shallow depression in anterior $2 / 3$, strongly rugulose laterally, almost parallel-sided(Fig. 1B); T2 sub-rectangular, smooth, suture between T2 and T3 weak; T3 $1.2 \times$ longer than T2, smooth with irregular rows of sparse setae, remaining tergites smooth (Fig. 1B); hypopygium small, shorter than tip of metasoma; ovipositor sheath short, approximately $1.2 \times$ as long as second hind tarsomere, acute apically and sparsely setose.; hypopygium small, slightly shorter than tip of metasoma; ovipositor sheath short, approximately $1.3 \times$ as long as second hind tarsomere, acute apically, almost without setae.

\section{Colour}

Body generally black, T1 brown, palps yellow, legs yellow except hind coxae, hind tibial spurs yellow, wings hyaline with infuscations apically, venation brown, setae on wings and body brown, pterostigma yellow basally half, rest black.

\section{Male}

Unknown.

\section{Distribution}

Saudi Arabia (Asir).
Host

Unknown

Etymology.

The name of the species originated from its type locality.

\section{Variation}

Body length 2.1-2.2 $\mathrm{mm}$ and length of fore wing $1.7-1.8 \mathrm{~mm}$. The number of carinae dividing the scutellar lunules varies from six-seven.

\section{Microplitis faifaicus Ghramh and Ahmad, sp. nov.} (Fig. 2 A-C)

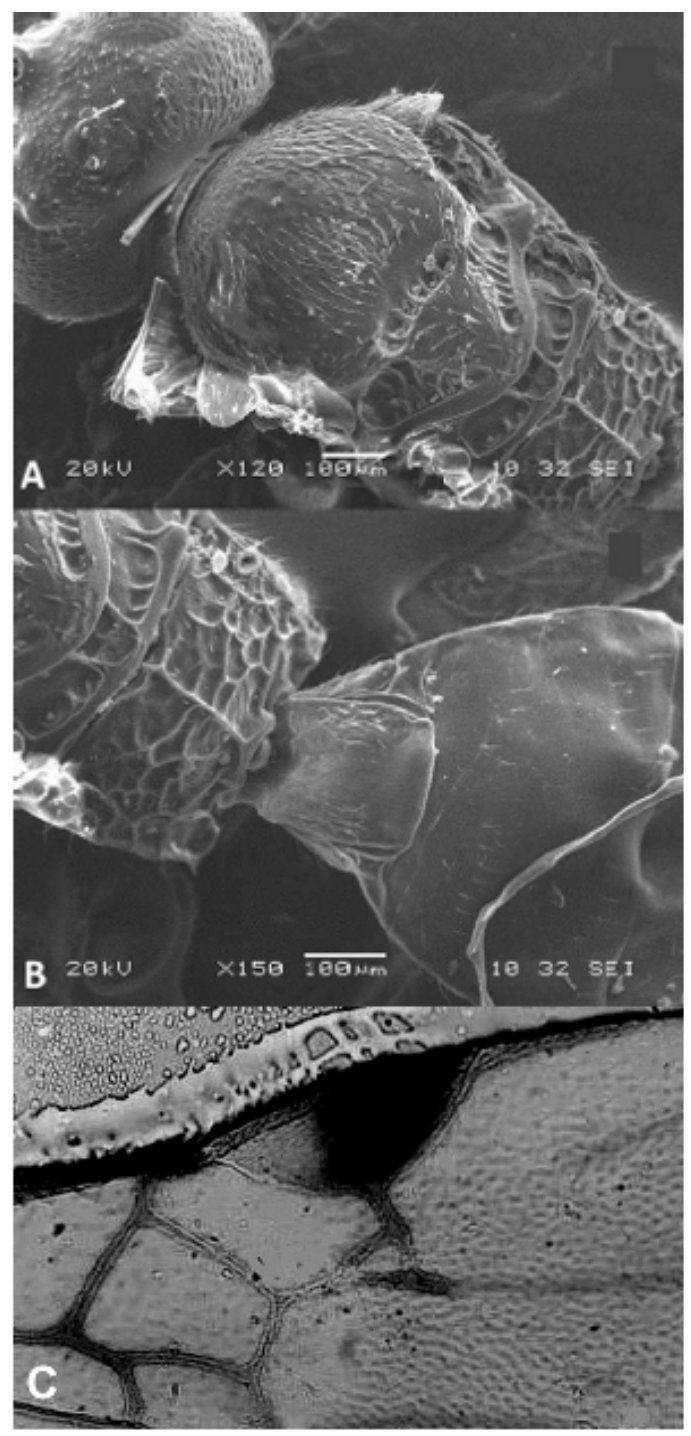

Fig. 1. Microplitis tihamicus sp. nov: A, Mesosoma, dorsal lateral view; B, Metasoma, dorsal view; C, Forewing (10x). 


\section{Differential diagnosis}

The new species closely resembles with Microplitis hova (Granger, 1949) from Madagascar; however, it can be separated from all other described species of Microplitis in the afro-tropical region by the combination of the following features: entirely dark brown to black coloration (excluding all legs which are yellowish except hind coxae), infuscate wings, forewing areolate quadrangular shape and high altitudinal distribution.

This new species differs from M. tihamicus sp. nov., by having: forewing areolate quadrangular (in M. tihamicus forewing areolate almost triangular); propodeum coarsely reticulate rugose, with an impression of medial longitudinal carina originated with same texture of rugosity (in $M$. tihamicus propodeum reticulate rugose with a percurrent medial longitudinal carina); vein ISR $+\mathrm{M}$ straight (in $M$. tihamicus vein ISR+M curved); ovipositor sheath acute apically, almost without setae (in M. tihamicus ovipositor sheath rounded apically, with few setae).

\section{Material examined}

Holotype: + , Saudi Arabia: Faifa, $\left(17^{\circ} 13^{\prime} 25.3^{\prime \prime} \mathrm{N}\right.$ $\left.43^{\circ} 05^{\prime} 25.8^{\prime \prime} \mathrm{E}\right)$, 7.III.2016, Malaise trap, Z. Ahmad leg. (ZDKKU). Paratype, 1 우, with same data as holotype (HB12, ZDKKU).

\section{Description}

Female: body length: $2.5 \mathrm{~mm}$; length of fore wing: $2.3 \mathrm{~mm}$; length of antenna: $2.0 \mathrm{~mm}$.

\section{Head}

Head ca. $2 \times$ as wide as long in dorsal view, subcircular in anterior view; length of eye $0.7 \times$ as long as temple in dorsal view; temple and vertex shiny with indistinct punctures; OOL: POL: $\mathrm{AOL}: \mathrm{OD}=6: 3: 2: 1.5$; inner margin of eyes subparallel; face distinctly convex medially, and punctuate-rugose with faint trace of median longitudinal carina; clypeus smooth and evenly convex; malar space ca. $2.1 \times$ as long as its basal width of mandible; vertex dull with micro punctures; lateral temples punctuaterugulose and densely setose; antenna about as long as body with 14-segmented flagellomeres, F 1 as long as F 2, apical flagellomere pointed.

\section{Mesosoma}

Mesosoma $1.35 \mathrm{x}$ as long as wide; mesoscutum densely setose, rugulose punctate, notauli indistinct (Fig. $2 \mathrm{~A}$ ); scutellum with few punctures, scutellar lunules wide divided by seven carinae, medio-posterior depression of scutellum elliptical (Fig. 2A); propodeum coarsely reticulate rugose, with an impression of medial longitudinal carina originated with same texture of rugosity (Fig. 2A); mesopleuron rugulose anteriorly, rest is smooth; length of hind femur $3.0 \times$ its width; length of hind tibia $6.1 \times$ its width; length of hind tibial spurs $0.33,0.26 \times$ hind basitarsus; hind tarsal claw normal size.

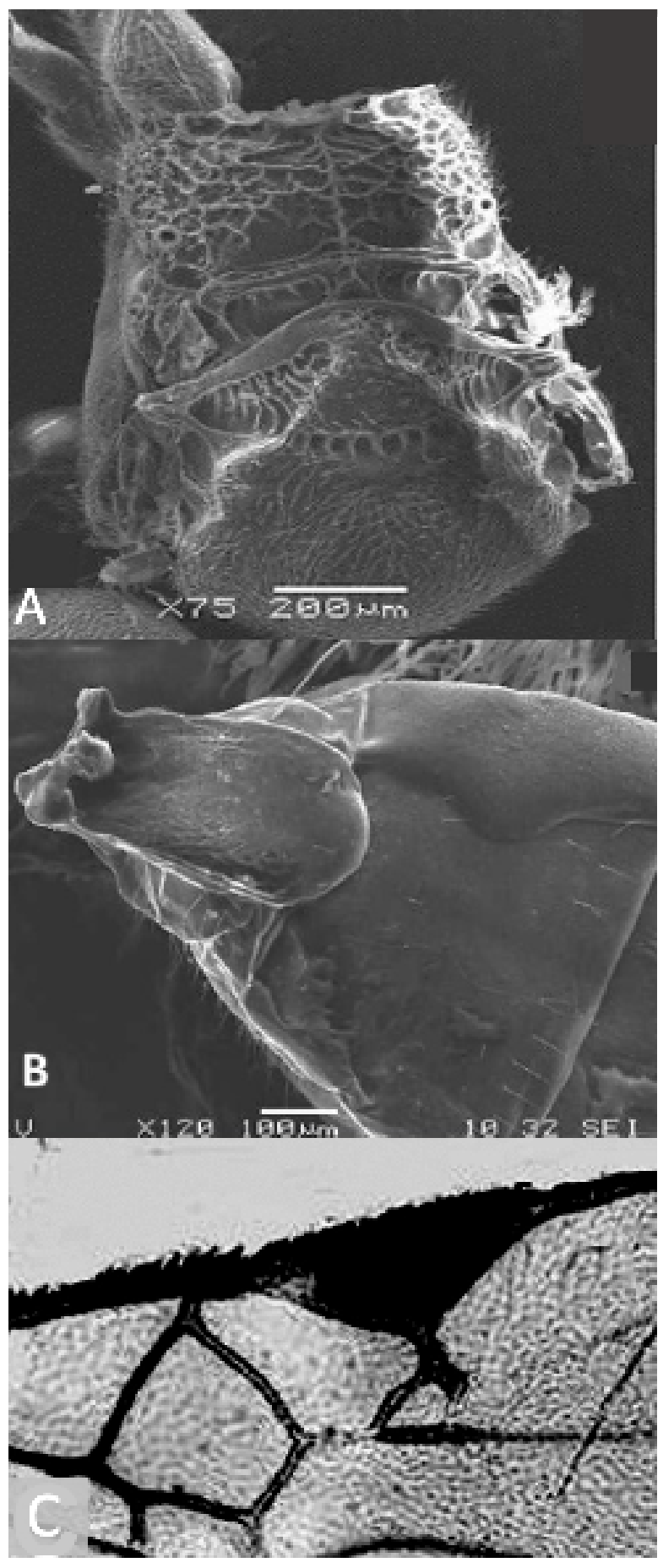

Fig. 2. Microplitis faifaicus sp. nov: A, Mesosoma, dorsal lateral view; B, Metasoma, dorsal view; C, Forewing (10x). 
Wings

Fore wing $2.7 \times$ as long as wide; pterostigma $2.0 \times$ as long as wide; 1-R1 ca. as long as pterostigma; 1-M almost straight; 1SR+M slightly curved downwards (Fig. 2C); areolet quadrangular, 3-SR $0.75 \times$ as long as vein $r$ (Fig. 2C); 1-CU1 $0.33 \times$ as long as 2-CU1; 2- CU1 almost straight; angle between $\mathrm{C}+\mathrm{SC}+\mathrm{R}$ and $1-\mathrm{SR} 70^{\circ}$.

\section{Metasoma}

T1 $2.0 \times$ as long as wide with a shallow depression in anterior $2 / 3$, moderately rugulose laterally, almost slightly broadening posteriorly (Fig. 2B); T2 sub-rectangular, smooth, suture between T2 and T3 weak; T3 $1.25 \times$ longer than T2, smooth with irregular rows of sparse setae, remaining tergites smooth (Fig. 2B); hypopygium small, shorter than tip of metasoma; ovipositor sheath short, approximately $1.2 \times$ as long as second hind tarsomere, acute apically and sparsely setose.; hypopygium small, shorter than tip of metasoma; ovipositor sheath short, approximately $1.2 \times$ as long as second hind tarsomere, acute apically, almost without setae.

\section{Colour}

Body generally black, T1 brown, palps yellow, legs yellow except hind coxae, hind tibial spurs yellow, wings infuscate, venation brown, setae on wings and body brown, pterostigma yellow basally $1 / 3$, rest is black.

Male

Unknown.

Distribution

Saudi Arabia (Asir).

Host

Unknown

Etymology locality.

The name of the species originated from its type

\section{Variation}

Body length 2.2-2.5 mm. The number of carinae dividing the scutellar lunules varies from six-seven. Scutellum smooth and setose.

\section{Microplitis khamisicus Ghramh and Ahmad, sp. nov.} (Fig. 3 A-C)

\section{Material examined}

Holotype: + , Saudi Arabia: Khamis Mushyat (18²0’39.7'N 42³9'18.7'E), 7.IV.2017, Malaise trap, Z.
Ahmad leg. (ZDKKU). Paratype, 2 , , with same data as holotype (HB-13, ZDKKU).

\section{Differential diagnosis}

The new species closely resembles with Microplitis bambusanus (de Saeger, 1944) from Congo and Rwanda; however, This species can be separated from all other described species of Microplitis in the afro-tropical region by the combination of the following features: body covered with dense setae, entirely dark brown to black coloration (excluding all legs and laterotergites dorsolaterally which are yellowish), infuscate wings, pterostigma black, notauli well defined and T1 slightly widening apically.

This new species can be easily separated from other new species viz., $M$. tihamicus and $M$. faifaicus by having: body size large $3.0-3.1 \mathrm{~mm}$ (in $M$. tihamicus and $M$. faifaicus body length 2.0-2.5mm); head and mesosoma densely setose (in M. tihamicus and M. faifaicus head and mesosoma moderately to sparsely setose); notauli present (in M. tihamicus and M. faifaicus notauli absent); laterotergites yellowish dorsolaterally (in M. tihamicus and M. faifaicus laterotergites blackish brown)

\section{Head}

Head ca. $2 \times$ as wide as long in dorsal view, subcircular in anterior view; length of eye $0.8 \times$ as long as temple in dorsal view; temple and vertex shiny with indistinct punctures; OOL: POL: AOL: OD = 9: 6: 4: 3; inner margin of eyes subparallel; face distinctly convex medially, and punctuate-rugose with a median longitudinal carina; clypeus smooth and evenly convex; malar space ca. $1.8 \mathrm{x}$ as long as its basal width of mandible; vertex dull with micro punctures; lateral temples punctuate-rugulose and densely setose (Fig. 3A); occiput smooth and shiny; antenna about as long as body with 14-segmented flagellomeres, F 1 as long as F 2 , apical flagellomere pointed.

\section{Mesosoma}

Mesosoma ca. $1.5 \times$ as long as wide; mesoscutum densely setose, largely punctate, its posterior surface rather smooth with a median longitudinal rugose groove merging posteriorly into the notauli (Fig. 3A); notauli well defined, rugose and meeting posteriorly before scutellar sulcus (Fig. 3A); scutellum densely setose with few punctures, scutellar lunules wide divided by six carinae (Fig. 3A); propodeum coarsely reticulate rugose with a percurrent medial longitudinal carina; mesopleuron rugulose anteriorly, rest is smooth; length of hind femur $4.0 \times$ its width; length of hind tibia $7.1 \times$ its width; length of hind tibial spurs $0.27,0.20 \times$ hind basitarsus; hind tarsal claw normal size. 
Wings

Fore wing $2.3 \times$ as long as wide; pterostigma $2.0 \times$ as long as wide; $1-\mathrm{R} 1 \mathrm{ca}$. as long as pterostigma; $1-\mathrm{M}$ almost straight; 1SR+M straight (Fig. 3C); areolet quadrangular, 3-SR $0.4 \times$ as long as vein $r$ (Fig. 3C); 1 -CU1 $0.30 \times$ as long as 2-CU1; 2- CU1 curved; angle between $\mathrm{C}+\mathrm{SC}+\mathrm{R}$ and $1-\mathrm{SR} 75^{\circ}$.

\section{Metasoma}

T1 $1.8 \times$ as long as wide, smooth with shallow depression in anterior half, slightly broadening posteriorly (Fig. 3B); T2 sub-rectangular, smooth, its median field slightly raised, suture between T2 and T3 weak (Fig. 3B); T3 $1.2 \times$ longer than T2, smooth with irregular rows of sparse setae, remaining tergites smooth; hypopygium small, shorter than tip of metasoma; ovipositor sheath short, approximately $1.2 \times$ as long as second hind tarsomere, acute apically and sparsely setose.

\section{Colour}

Body generally black, $\mathrm{T} 1$ reddish brown, legs yellow except hind coxae, hind tibial spurs yellow, wings infuscate, venation brown, pterostigma black, setae on wings brown while setae on the head and thorax whitish, laterotergites 2 and 3 yellow dorsolaterally, T2 yellow dorsally.

Male

Unknown.

Distribution

Saudi Arabia (Asir).

Host

Unknown

Etymology locality.

The name of the species originated from its type

\section{Variation}

Body size 3.0-3.1 mm. The number of carinae dividing the scutellar lunules varies from six-seven, hind femur and tibia brown basally in few paratypes.

\section{ACKNOWLEDGEMENTS}

The authors would like to extend their appreciation to the Research Center for Advanced Materials Science (RCAMS), King Khalid University, Abha, KSA. The second author (ZA) extends his gratitude to the Research Center for Advanced Materials Science (RCAMS), King Khalid University for funding through research program RCAMS/KKU/04/20.

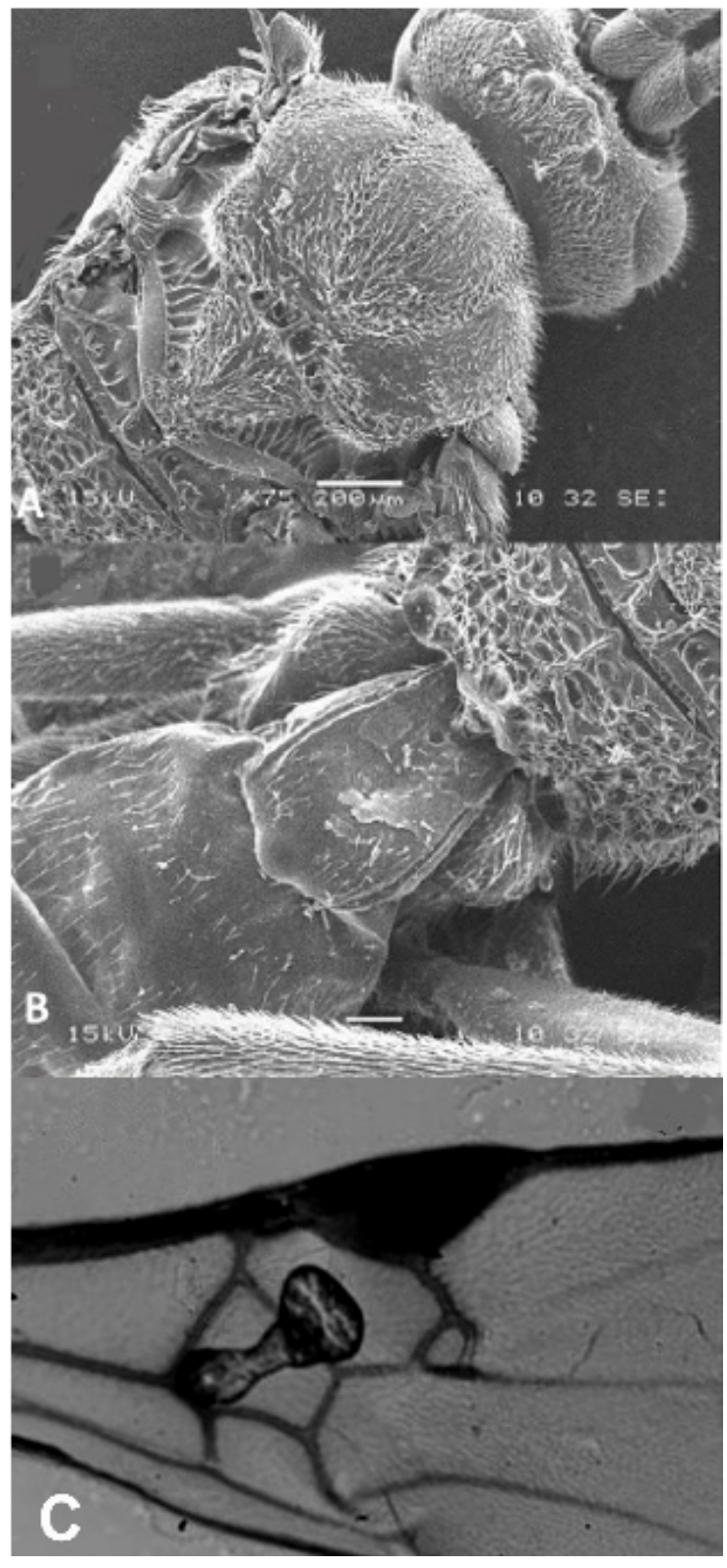

Fig. 3. Microplitis khamisicus sp. nov: A, Mesosoma, dorsal lateral view; B, Metasoma, dorsal view; C, Forewing (10x).

\section{Statement of conflict of interest}

The authors have declared no conflict of interest.

\section{REFERENCES}

Abdel-Dayem, M.S., Rasool, I., Elgharbawy, A.A., Nagel, P. and Aldhafer, H.M., 2018. Faunistic inventory and zoogeographical analysis of the ground beetles (Coleoptera, Carabidae) of Garf Raydah Nature Reserve, southwestern of Saudi 
Arabia, and description of a new species of Paussinae. Zootaxa, 4514: 341-371. https://doi. org/10.11646/zootaxa.4514.3.3

Alahmed, A.M., Kheir, S.M. and Al Khereiji, M.A., 2010. Distribution of Culicoides latreille (Diptera: Ceratopogonidae) in Saudi Arabia. J. Ent., 7: $227-$ 234. https://doi.org/10.3923/je.2010.227.234

Austin, A.D. and Dangerfield, P.C., 1992. Synopsis of Australasian Microgastrinae (Hymenoptera: Braconidae), with a key to genera and description of new taxa. Inverteb. Taxon, 6: 1-76. https://doi. org/10.1071/IT9920001

Austin, A.D. and Dangerfield, P.C., 1993. Systematics of Australian and New Guinean Microplitis Foerster and Snellenius Westwood (Hymenoptera: Braconidae: Microgastrinae), with a review of their biology and host relationships. Invertebr. Taxon, 7: 1097-1166. https://doi.org/10.1071/IT9931097

Cameron, P., 1906. On the Tenthredinidae and parasitic Hymenoptera collected in Baluchistan by Major C. G. Nurse. J. Bombay Nat. Hist. Soc., 17: 89-107.

Chen, J. and Song, D., 2004. Systematic studies on Microgastrinae of China (Hymenoptera: Braconidae). Fujian Science and Technology Publishing House, Fuzhou, pp. 354. (Chinese with English summary).

Cowie, R.H., 1989. The zoogeographical composition and distribution of the Arabian termitefauna. Biol. J. Linn. Soc., 36: 157-168. https://doi. org/10.1111/j.1095-8312.1989.tb00488.x

De Saeger, H., 1944. Microgasterinae (Hymenoptera Apocrita). Fam. Braconidae. Exploration du Parc National Albert. Mission G.F. de Witte (19331935). 47: 1-342.

Eady, R.D., 1968. Some illustrations of microsculpture in the Hymenoptera. In Proc. R. Entomol. Soc. London. Series A, 43: 66-72. https://doi. org/10.1111/j.1365-3032.1968.tb01029.x

Eady, R.D., 1974. The present state of nomenclature of wing venation in the Braconidae (Hymenoptera); its origins and comparison with related groups. $J$. Ent., Ser. B. (Taxonomy), 43: 63-72. https://doi. org/10.1111/j.1365-3113.1974.tb00089.x

El-Hawagry, M.S. and Al Dhafer, H.M., 2015. Five new records of bee flies (Bombyliidae, Diptera) from Saudi Arabia with zoogeographical remarks. ZooKeys, 489: 125-133. https://doi.org/10.3897/ zookeys.489.8794

Fernández-Triana, J.L., Whitfield, J.B., Smith M.A., Kula, R.R., Hallwachs, W. and Janzen, D.H., 2015. Revision of the genera Microplitis and Snellenius (Hymenoptera, Braconidae, Microgastrinae) from area de Conservacion Guanacaste, Costa Rica, with a key to all species previously described from Mesoamerica. Deut. Ent. Z., 62: 137-201.

Fernandez-Triana, J., Shaw, M.R., Boudreault, C., Beaudin, M. and Broad, G.R., 2020. Annotated and illustrated world checklist of Microgastrinae parasitoid wasps (Hymenoptera, Braconidae). ZooKeys, 920: 1-1089. https://doi. org/10.3897/ zookeys.920.39128

Fernandez-Triana, J. and Boudreault, C., 2018. Seventeen new genera of microgastrine parasitoid wasps (Hymenoptera, Braconidae) from tropical areas of the world. J. Hymen. Res., 64: 25-140. https://doi.org/10.3897/jhr.64.25453

Fernández-Triana, J., and van Achterberg, C., 2017. Order Hymenoptera, family Braconidae subfamily Microgastrinae from the Arabian Peninsula. Arthrop. Fauna U. A. E., 6: 275-321.

Fernández-Triana, J.L. and Ward, D., 2017. Microgastrinae, wasps of the world. Available from http://microgastrinae.myspecies.info/ (accessed February 12, 2018).

Foerster, A., 1862. Synopsis der Familien und Gattungen der Braconen. Ver. Nat. Ver. Preussisch. Rheinlande und Westfalens, 19: 225-288.

Ghramh, H.A. and Ahmad, Z., 2016. A Checklist of Ichneumonoidea (Hymenoptera: Ichnemonidae: Braconidae) from Kingdom of Saudi Arabia. Asian J. Agric. Life Sci., 1: 18-22.

Granger, C., 1949. Braconides de Madagascar. Mém. de l'Institute Scientifique de Madagascar, Série A, 2: $1-428$.

Hölzel, H., 1998. Zoogeographical features of Neuroptera of the Arabian Peninsula. Acta Zool. Fenn., 209: 129-140.

Mason, W.R.M., 1981. The polyphyletic nature of Apanteles Foerster (Hymenoptera: Braconidae): A phylogeny and reclassification of Microgastrinae. Mem. ent. Soc. Can., 115: 1-147. https://doi. org/10.4039/entm113115fv

Nees von Esenbeck, C.G., 1834. Hymenopterorum Ichneumonibus Affinium Monographicae, Genera Europaea et Species Illustratae. Vol. 1. J.G. Cottae1, Stuttgart et Tubingen, pp. 320. https://doi. org/10.5962/bhl.title. 26555

Nixon, G.E.J., 1970. A revision of the northwestern European species of Microplitis Forster (Hymenoptera: Braconidae). Bull. Br. Mus. nat. Hist. Ent., 25: 1-30.

Papp, J., 1979. Braconidae (Hymenoptera) from Tunisia, 1. Folia Ent. Hung., 32: 175-187.

Ranjith, A.P., Rajesh, K.M. and Nasser, M. 2015. 
Taxonomic studies on oriental microplitis foerster (Hymenoptera: Braconidae, Microgastrinae) with description of two new species from South India. Zootaxa, 3963: 369-415. http://dx.doi.org/10.11646/ zootaxa.3963.3.4

Sclater, P.L., 1858. On the general geographical distribution of the class Aves. J. Proc. Linn. Soc., 2: 130-145. https://doi.org/10.1111/j.1096-3642.1858. tb02549.x

Sharaf, M.R., Al Dhafer, H.M. and Aldawood, S.A., 2014. First record of the myrmicine ant genus Meranoplus Smith, 1853 (Hymenoptera: Formicidae) from the Arabian Peninsula with description of a new species and notes on the zoogeography of southwestern Kingdom Saudi Arabia. PLoS One, 9: e111298. https://doi.org/10.1371/journal.pone.0111298

Shenefelt, R.D., 1973. Braconidae 5, Microgasterinae and Ichneutinae. Part 9. In: Hymenopterorum Catalogus (eds. J. van der Vecht and R.D. Shenefelt). Dr W. Junk, Gravenhage, pp. 669-812. van Achterberg, C., 1993. Illustrated key to the subfamilies of the Braconidae (Hymenoptera: Ichneumonoidea). Zool. Verh., 283: 1-189.

Viereck, H.L., 1914. Type species of genera of ichneumon flies. Bull. U. S. natl. Mus., 83: 1-186. https://doi.org/10.5479/si.03629236.83.1

Wallace, A.R., 1876. The geographical distribution of animals, with a study of the relations of living and extinct faunas as elucidating the past changes of the earth's surface. Vols. 1, 2. Macmillan and Co., London, pp. 503, 607. https://doi.org/10.5962/bhl. title.46581

Yu, D.S., van Achterberg, C. and Horstmann, K., 2016. Taxapad 2016, www.taxapad.com, Nepean, Ontario, Canada.

Zhang, W., Song, D. and Chen, J., 2019. Two new species of the genus Microplitis Förster, 1862 (Hymenoptera, Braconidae, Microgastrinae) from China. ZooKeys, 859: 49-61. https://doi. org/10.3897/zookeys.859.31720 